\title{
A method to induce tumor marker release
}

\begin{abstract}
Objective: Tumor markers are considered unreliable because their levels are low and detection methods are not sufficiently sensitive and specific. Furthermore, there is no clear correlation with tumor size, because the biological characteristics of tumor markers remain largely unknown. We previously reported a reliable tumor marker combination assay in the journal Cancer in 1994 using 3 types of marker, tumor-specific, tumor- associated and growth-related makers. Here, we report a new method to induce tumor marker release and discuss related clinical applications, especially, for cancers without specific tumor markers.
\end{abstract}

Methods: The human gastric cancer line $\square$ MKN-45 (20million cells) was transplanted into nude mice. On days 20 and 27 after tumor cell transplantation tumor, 2500 IU vitamin A (retinoic acid) was administered intramuscularly. After 3 hours, the tumor bearing nude mice were treated at $40^{\circ} \mathrm{C}$ for 20 minutes using an infrared red ray sauna bath to induce tumor marker release. Carcinoembryonic antigen (CEA) was measured at 0, 6, 24, and 48 hours. The same doses of sodium bicarbonate and palmitic acid were used as controls. We examined the correlation of cancer stage and tumor marker parameters, including the maximum CEA value (CEAmax), the maximum differences in CEA levels ( $\triangle$ CEA: range of tumor marker levels), average variation $(\triangle \mathrm{CEA} / \mathrm{h})$ and the expected maximum quantity ( $\triangle \mathrm{CEA} / \mathrm{h}$ xCEAmax), after combined treatment with vitamin $\mathrm{A}$ and hyperthermia in nude mice and human.

Results: Tumor markers have been considered substances released by broken cancer cells. However, we observed that tumor marker release is induced by hyperthermia treatment with vitamin $\mathrm{A}$ and is inhibited by treatment with actinomycin $\mathrm{D}$ or cycloheximide via CEA mRNA. Tumor marker release might be related to tumor markers induced by mRNA synthesis. We designed a method to estimate the correlation between the presence of tumors and tumor size, using tumor-marker parameters.

Conclusion: We can estimate the tumor size with the maximum value(Vmax), maximum differences in value $(\Delta \max )$, the average variation $(\Delta \max / \mathrm{h})$ and expected maximum quantity $(\Delta \operatorname{maxx} V \max )$ based on the release of tumor markers by combining vitamin $\mathrm{A}$ and hyperthermia treatment even if tumor lacks specific tumor marker.

Keywords: induction of tumor marker, maximum difference in value $(\Delta \max )$ maximum value $(V \max )$, the average variation $(\mathrm{Vmax} / \mathrm{h})$, expected maximum quantity $(\mathrm{V} \max \Delta \max / \mathrm{h})$
Volume I Issue 3 - 2018

Tsuneo Kobayashi

International cancer prevention center, Japan

Correspondence: Tsuneo Kobayashi, International cancer prevention center, Chiba city, 3-2I-I,Takasu, Mihamaku, Chiba city 26I-0004, Japan, Tel 043-306-26 I I, Fax 043-279-42 I I, Emailft1992@vega.ocn.ne.jp

Received: April 12, 2018 | Published: May 02, 2018

\section{Introduction}

Although, Kitamura ${ }^{1}$ reported that the maximum range variation for carcinoembryonic antigen (CEA) levels in a healthy body is narrow for many years. ${ }^{1}$ We observed that serum tumor markers are not constant in any cancer case. To date, the induction of tumor marker release (TMR) has never been applied to patients during an initial examination in an outpatient clinic. Prior to patient examination, we verified the utility of this method in animal and tissue culture experiments.

\section{Basic experiments}

a) Long-term induction of tumor marker release (TMR) ${ }^{2}$

We examined the correlation between tumor size and tumor marker parameters including the maximum level of the tumor marker CEA (CEAmax), the change in the CEA value ( $\triangle \mathrm{CEA})$, the rate of change of the CEA value $(\triangle \mathrm{CEA} / \mathrm{h})$, and $\triangle \mathrm{CEA} / \mathrm{h} \times \mathrm{CEAmax}$. We revealed long-term (Figure 1) and short-term (Figure 2) TMR induction; CEA release was induced by vitamin A (Chocola ${ }^{\circledR}$, retinoic acid 25 $\sim 125 \mu \mathrm{M})$ and hyperthermia $\left(40^{\circ} \mathrm{C}\right.$ for $\left.20 \mathrm{~min}\right)$. CEA was assayed with an enzyme immunoassay using a CEA-EIA kit (Hoffman-Roche

\section{Co., Basel, Switzerland)}

b) Short-term induction of TMR (Figure 2)

TMR was characterized by short-term and long-term biphasic induction reactions. Because short-term TMR induction is difficult to use in clinical practice, long-term TMR induction (1 to 2days) is conventionally used.

c) This phenomenon was unchanged. Even when the mouse model changed from CD-1/nu.nu to Balb-nu/nu; similar results were obtained.

d) TMR was induced 20 and day 27 days after transplantation. Correlation of tumor size with the following parameters was assessed: CEAmax, $\triangle \mathrm{CEA}, \triangle \mathrm{CEA} / \mathrm{h}$, and $\triangle \mathrm{CEA} / \mathrm{hxCEAmax.} \mathrm{A}$ good correlation was obtained.

e) Study of cultured cells ${ }^{3}$

CEA-producing human cultured cancer cells (MKN-45) were treated with vitamin A (retinoic acid, 75 to $125 \mu \mathrm{M}$ ). After treatment, cell growth was slightly inhibited, and intracellular and extracellular CEA levels increased (Figure 3). 


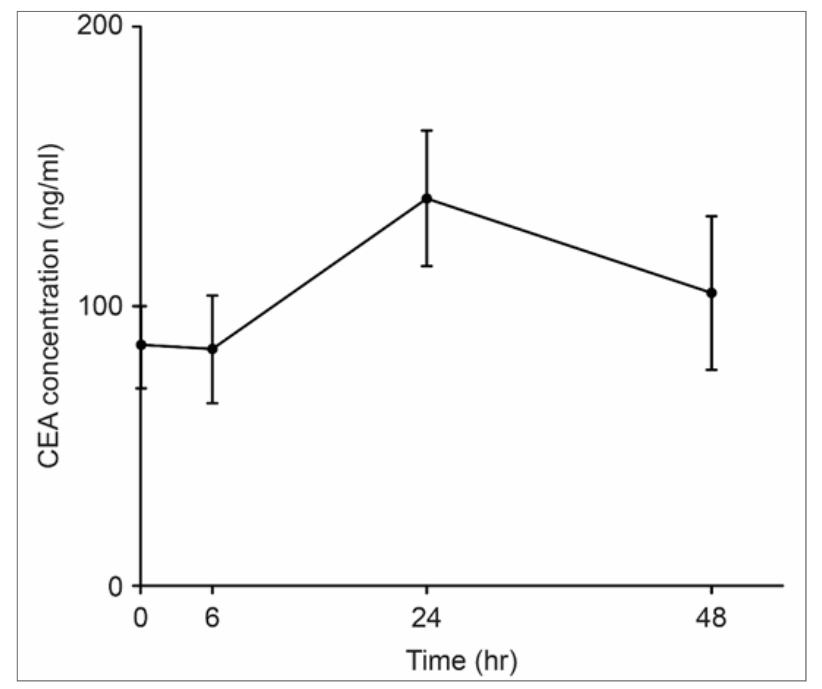

Figure ITMR induction was performed out on day of 16 after transplantation of MKN-45 (20million cells) in the long term. Three hours after intramuscular injection of vitamin A (2500 IU), hyperthermia treatment was performed at $40^{\circ} \mathrm{C}$ for 20 minutes. The blood was withdrawn from the orbital vein at $0,6,24$ and 48 hours. CEA was assayed by the CEA-EIA kit (Abbott, Co. Ltd).

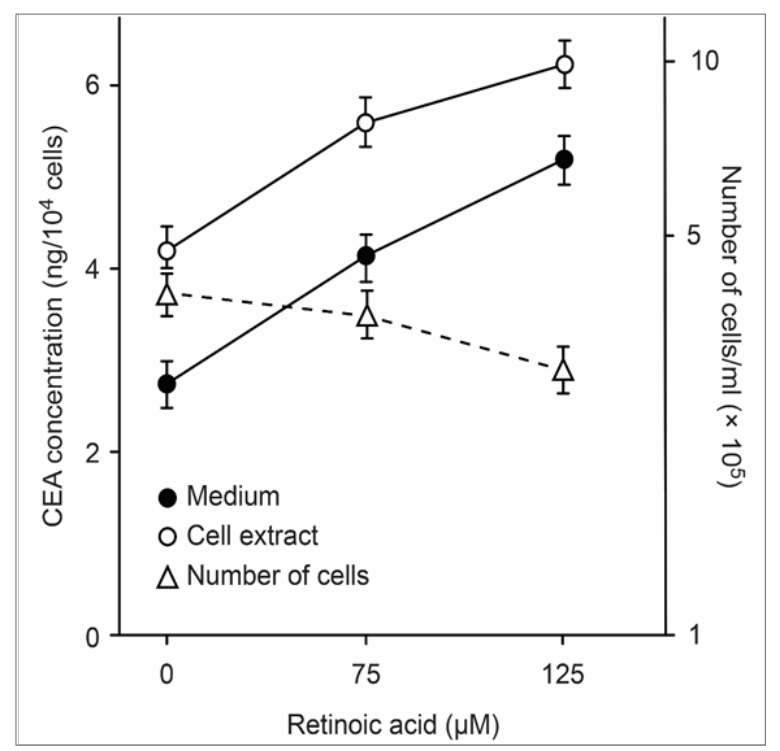

Figure 3 Dose-dependency of the CEA increase induced by retinoic acid in MKN-45 cells. The cells were incubated in the presence of retinoic acid at various concentrations for 2 days. The CEA content in the medium ( $\bullet$ ) and in cell extract $(\circ)$ and the number of cells $(\Delta)$ was measured by the methods described in Section 2.

f) Next, MKN-45 cells were treated with vitamin A $(125 \mu \mathrm{M}$ retinoic acid) combined with hyperthermia $\left(40^{\circ} \mathrm{C}\right.$ for $30 \mathrm{~min}$.) to investigate proliferation over time and changes in intracellular and extracellular CEA levels (Figure 4). Treatment with vitamin A and hyperthermia increased intracellular and extracellular CEA levels. CEA was induced by vitamin A, and further treatment with hyperthermia synergistically induced CEA.

g) Cultured MKN-45 cells $\left(3 \times 10^{5} /\right.$ tube $)$ were used to examine whether CEA released from CEA-producing tumors is induced

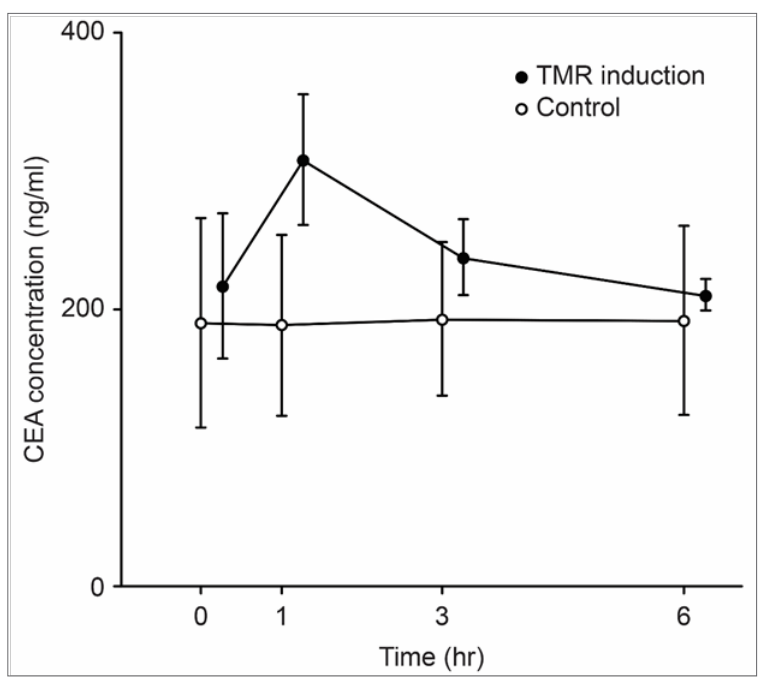

Figure 2TMR induction was performed out on day of 16 after transplantation of MKN-45 (20million cells) in the short term. Three hours after intramuscular injection of vitamin A (2500IU), hyperthermia treatment was added at $40^{\circ} \mathrm{C}$ for 20 minutes. The blood was collected from orbital vein after 0 , I, 3 , and 6 hours. CEA was assayed by the CEA-EIA kit (Abbott, Co. Ltd). In the control, the same amounts of $\mathrm{HCO}$ and palmitic acid were injected.

by treatment with vitamin A and hyperthermia and inhibited by treatment with actinomycin $\mathrm{D}(1 \mathrm{ng} / \mathrm{mL})$ and cycloheximide $(0.2 \mu \mathrm{g} / \mathrm{mL})$, which are protein synthesis inhibitors. The open white columns indicate the control group. The solid black columns indicate the group treated with vitamin A and hyperthermia. The columns with the slanted lines indicate the group treated with vitamin A, hyperthermia and actinomycin D. The columns with vertical lines indicate the group treated with vitamin A, hyperthermia, and cycloheximide. As shown in Figure 5, CEA release was induced by combined treatment with vitamin $\mathrm{A}$ and hyperthermia. Because mRNA inhibitors prevent this reaction, the protein synthesis observed was newly induced. There was a trend toward increased CEA release over time after stimulation by vitamin A and hyperthermia. CEA release was consistently inhibited by treatment with actinomycin $\mathrm{D}$ or cycloheximide. From these studies, even for small tumors, we can estimate the size of hidden tumors in the body by utilizing tumor marker parameters such as the maximum difference in a value $(\Delta \max )$, the maximum value(Vmax), the average variation $(\Delta \max / \mathrm{h})$ and the expected maximum quantity $(\Delta \max / \mathrm{h} x V \max )$. Therefore, we performed a tumor marker induction experiment with specific patients (Table 1). The times of the final blood collection and the number of patients for each blood sampling are shown in Table 2.

\section{Methods for inducing TMR in humans ${ }^{4}$}

A total of 138 patients presented at a holistic medical outpatient clinic and received a histopathological definitive diagnosis. The tumor size was 1 to $2 \mathrm{~cm}$ in diameter for cancer stage $\mathrm{G}_{1}, 2$ to $5 \mathrm{~cm}$ in diameter for cancer stage for $\mathrm{G}_{2}$, and $5 \mathrm{~cm}$ or greater in diameter for cancer stage $G_{3}$, which was classified as advanced cancer. Stage $\mathrm{G}_{1}, \mathrm{G}_{2}$ and $\mathrm{G}_{3}$ numbers included 61,37 and 40 cases, respectively. As a control, the induction of TMR was studied in 11 patients without cancer and in 4 healthy subjects. Tumor marker release was examined. Table 1 shows the types of cancer. 
Table I Diagnosis subject who have various cancer, were utilized in TMR experiment

\begin{tabular}{ll}
\hline Carcinoma & No. of patients \\
\hline Breast & 25 \\
Stomach & 21 \\
Colon & 15
\end{tabular}

\begin{tabular}{ll} 
Rectum & 10 \\
Uterus & 8 \\
Lung & 8 \\
Larynx & 3 \\
Liver & 5 \\
Kidney & 4 \\
Nose & 2 \\
Esophagus & 2 \\
Malognant Lymphoma & 2 \\
Hodgkin disease & 2 \\
Seminoma & 4 \\
Leukemia & 2 \\
Miscellaneous & 25 \\
Controls & \\
Healthy individuals & 4 \\
Non-cancer patient & 11 \\
\hline
\end{tabular}

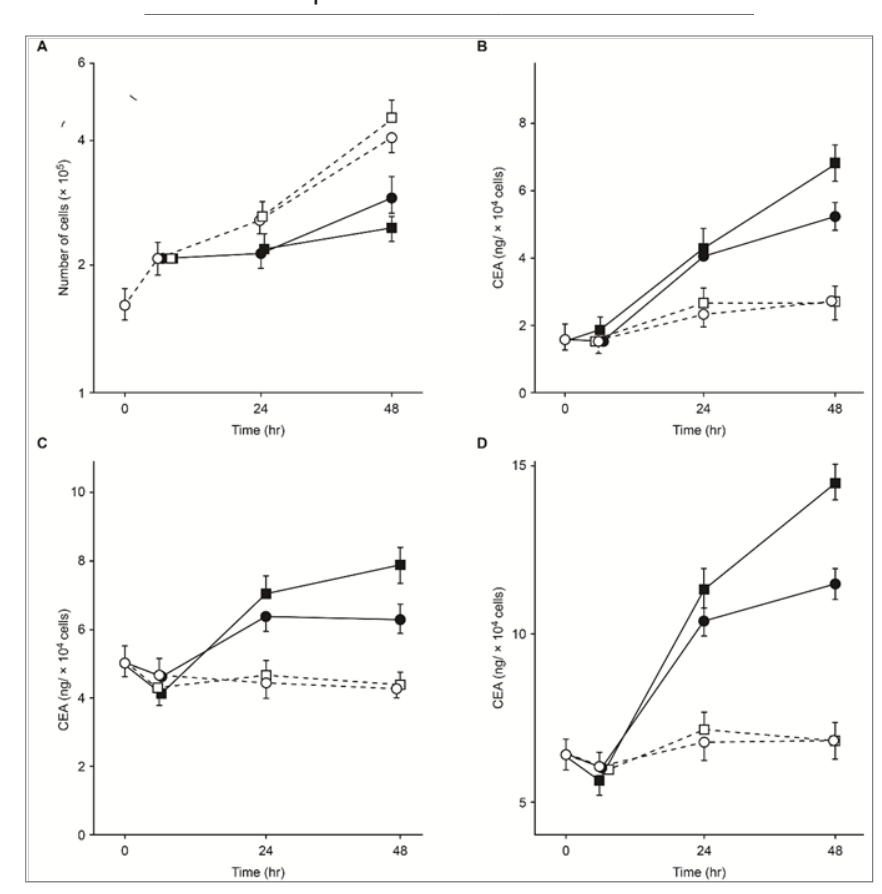

Figure 4 The time course of CEA increase induced by retinoic acid and in combination with hyperthermia in MKN-45 cells. Cells were continuously treated with or without $125 \mu \mathrm{M}$ retinoic acid in culture tubes. Then, the cells were heated at $40^{\circ} \mathrm{C}$ for $30 \mathrm{~min}$ immediately after the retinoic acid was added. All of the points represent the mean value of three tubes. ( $)$ Control. ( $\square$ ) hyperthermia: $(\bullet)$ retinoic acid: $(\boldsymbol{\bullet})$ retinoic acid+ hyperthermia. (A). Cell growth: (B)-(D) CEA levels.
Table 2 Times of final blood collection and number of patients for each blood sampling

\begin{tabular}{|c|c|c|c|c|c|c|c|c|}
\hline \multirow{3}{*}{$\begin{array}{l}\text { Induction } \\
\text { period after } \\
\text { hyperthermia } \\
\text { (h) }\end{array}$} & \multicolumn{8}{|c|}{ Number of cases } \\
\hline & \multicolumn{4}{|c|}{ Four markers } & \multicolumn{4}{|c|}{ Five markers } \\
\hline & $\mathbf{G}_{1}$ & $\mathbf{G}_{2}$ & $\mathbf{G}_{3}$ & Total & $\mathbf{G}_{1}$ & $\mathbf{G}_{2}$ & $\mathbf{G}_{3}$ & Total \\
\hline 6 & 11 & 11 & 9 & 31 & I & 0 & 2 & 3 \\
\hline 8 & 8 & 1 & 5 & 14 & 5 & 0 & 3 & 8 \\
\hline 24 & 20 & 9 & 4 & 33 & 12 & 5 & 4 & 21 \\
\hline 48 & 22 & 16 & 22 & 60 & 12 & 12 & 9 & 33 \\
\hline Total & 61 & 37 & 40 & 138 & 30 & 17 & 18 & 65 \\
\hline
\end{tabular}

CEA, ferritin (FT), AFP, and FT/Fe in the case of four markers

CEA, ferritin (FT), AFP, FT/Fe, and sialic acid in the case of five markers

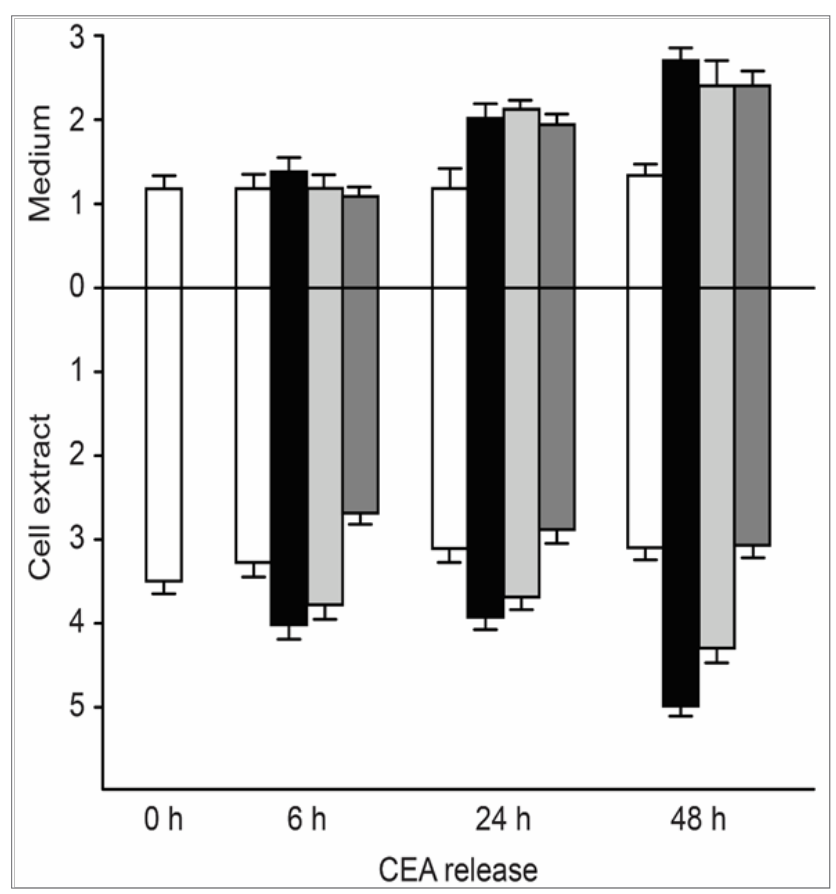

Figure 5 Effects of mRNA transcription or protein synthesis inhibitors on retinoic acid and hyperthermia-mediated increases in CEA content in MKN-45 cells. Cells were simultaneously exposed to $75 \mu \mathrm{M}$ retinoic acid and either actinomycin $D(\mathrm{Ing} / \mathrm{ml})$ or cyclohexamide $(0.2 \mu \mathrm{g} / \mathrm{ml})$ followed by hyperthermia $\left(40^{\circ} \mathrm{C}, 30 \mathrm{~min}\right)$. After 6,24 and $48 \mathrm{~h}$. cells and media were collected and analyzed for CEA. ( $\square$ )Control: ( () ) retinoic acid + hyperthermia: ( ) retinoic acid + hyperthermia + actinomycinD: () retinoic acid + hyperthermia + cyclohexamide.

\section{Determination of tumor markers}

CEA levels were determined by enzyme immunoassay with kits obtained from Abbott Co., Ltd. The cut-off value for CEA(Vmax) in stage $\mathrm{G}_{1}$ and the cut-off value of $\Delta \max$ (hereafter referred to as $\Delta$ in Tables 3-5) determined as the difference between the maximum and minimum values, were found to be $4.4 \mathrm{ng} / \mathrm{ml}$ and $0.9 \mathrm{ng} / \mathrm{ml}$, respectively. The cut-off value of $\Delta \max$ per hour $(\Delta \max / \mathrm{h})$ and the cut-off value of $(\Delta \max / \mathrm{h}) \mathrm{xVmax}$ were calculated to be $0.1 \mathrm{ng} / \mathrm{ml}$.h and $0.25 \mathrm{ng}^{2} / \mathrm{ml}^{2}$.h, respectively. Values of ferritin, alpha-fetoprotein (AFP), silalic acid and the ratio of ferritin to serum iron (FT/ Fe) were 
also determined using four parameters $(\Delta \max , V \max , \Delta \max / \mathrm{h}$, and $\Delta(\Delta \max / \mathrm{h}) \mathrm{x} V \max )$. The cut-off values for each stage are shown in Table 3. To quantitatively assess ferritin levels, the SPAC-Ferritin kit (The First Radioisotope Research Institute, Tokyo, Japan) and RIAgnost Ferritin kit (Hoechst, Frankfurt, FRG) were used. The AFP level was determined by RIA (double antibody method). Sialic acid levels were determined by enzyme assay with neuraminidase. Serum iron $(\mathrm{Fe})$ was assayed with a Hitachi 705 autoanalyzer

Table 3 Cut-off values for tumor markers

\begin{tabular}{|c|c|c|c|}
\hline \multirow{2}{*}{ Tumor marker } & \multicolumn{3}{|c|}{ Cancer stage } \\
\hline & $\mathbf{G}_{1}$ & $\mathbf{G}_{2}$ & $\mathbf{G}_{3}$ \\
\hline \multicolumn{4}{|l|}{ CEA (ng/ml) } \\
\hline$V \max$ & 4.4 & 4.8 & 10 \\
\hline$\Delta$ & 0.9 & I & 1.5 \\
\hline$\Delta / \mathrm{h}$ & 0.1 & 0.12 & 0.25 \\
\hline$\Delta / \mathrm{h} \times V_{\max }$ & 0.25 & 0.35 & I \\
\hline \multicolumn{4}{|l|}{ FT SPAC (ng/ml) } \\
\hline Vmax & M:I50, F:65 & 190 & 300 \\
\hline$\Delta$ & 20 & 30 & 40 \\
\hline$\Delta / \mathrm{h}$ & 0.8 & 1.5 & 4 \\
\hline$\Delta / \mathrm{h} \times V_{\max }$ & 50 & 100 & 400 \\
\hline \multicolumn{4}{|l|}{ RIA } \\
\hline Vmax & $M: 200, F: 100$ & 300 & 450 \\
\hline$\Delta$ & $\mathrm{M}: 30, \mathrm{~F}: 40$ & $\mathrm{M}: 50, \mathrm{~F}: 40$ & 60 \\
\hline$\Delta / \mathrm{h}$ & 4 & 7 & 15 \\
\hline$\Delta / \mathrm{h} \times \mathrm{V} \max$ & 800 & 2,000 & 5,000 \\
\hline \multicolumn{4}{|l|}{ AFP (ng/ml) } \\
\hline Vmax & 10 & 20 & 50 \\
\hline$\Delta$ & 5 & 6 & 7 \\
\hline$\Delta / \mathrm{h}$ & 0.6 & 0.6 & 0.8 \\
\hline$\Delta / \mathrm{h} \times \mathrm{Vmax}$ & 3 & 4 & 8 \\
\hline \multicolumn{4}{|l|}{ Sialic acid (mg/dl) } \\
\hline Vmax & 66 & 70 & 73 \\
\hline$\Delta$ & 5 & 7 & 10 \\
\hline$\Delta / \mathrm{h}$ & 0.5 & 0.65 & 0.8 \\
\hline$\Delta / \mathrm{h} \times \mathrm{Vmax}$ & 30 & 35 & 45 \\
\hline \multicolumn{4}{|l|}{$\mathrm{FT} / \mathrm{Fe}(\mathrm{ng} / \mathrm{ml} / \mu \mathrm{g} / \mathrm{dl})$} \\
\hline SPAC & I & 2 & 3 \\
\hline RIA & 1.5 & 2.5 & 5 \\
\hline
\end{tabular}

\section{Preliminary results}

The cut-off value for each of the four parameters at the $G_{1}$ level was used for each tumor marker, and the number and rate of positive cases $\square$ for tumor stages $\left(G_{1}, G_{2}\right.$ and $\left.G_{3}\right)$ are shown in Table 3. When the cut-off value of $\triangle \max$ or $V \max$ at a $\mathrm{G}_{1}$ level was used for CEA, the rates for positive cases in stages $\mathrm{G}_{1}, \mathrm{G}_{2}$ and $\mathrm{G}_{3}$ were 64,62 and $70 \%$, respectively. When the cut-off value of $\Delta \max / \mathrm{h}$ or $(\Delta \max / \mathrm{h}) \mathrm{xVmax}$ was used, the rates for positive cases in stages $G_{1}, G_{2}$ and $G_{3}$ were 61,73 and $70 \%$ respectively. When any one of the four parameters were examined using the SPAC-ferritin kit to determine ferritin level, the rates of positive cases in $\mathrm{G}_{1}, \mathrm{G}_{2}$, and $\mathrm{G}_{3}$ were 54,65 and $86 \%$, respectively. When any one of the four parameters were examined using the RIA-gnost ferritin kit to determine the ferritin level, the rates for positive cases in $G_{1}, G_{2}$ and $G_{3}$ were 61,65 and $84 \%$, respectively. Thus, as the result of the determining the ferritin level with the above two ferritin kits, the rates for positive cases in stages $G_{1}, G_{2}$ and $G_{3}$ were 57,65 and $85 \%$, respectively. When any one of four parameters $(\Delta \max , V \max , \Delta \max / \mathrm{h}$, or $(\Delta \max / \mathrm{h}) \mathrm{x} V \max )$ were used for AFP, the rates of positive cases were 26,22 , and $43 \%$ respectively. AFP was very unreliable. When any one of these parameters was used for silalic acid, the rates of positive cases in $\mathrm{G}_{1}, \mathrm{G}_{2}$ and $\mathrm{G}_{3}$ were 77,82 and $89 \%$, respectively. Because the ratio of ferritin Vmax ( $\mathrm{ng} / \mathrm{ml})$ divided by serum iron $(\mathrm{Fe}, \mu \mathrm{g} / \mathrm{dl})$ for the same period is considered an important tumor marker, we determined the rate of positive cases before the release induction by combing vitamin A and hyperthermia (0hr). When the SPAC-ferritin kit was used, the rates for stages $G_{1}, G_{2}$ and $\mathrm{G}_{3}$ were 29,60 and $76 \%$, respectively. When the RIA-gnost ferritin kit was used, they were 52,59 and $84 \%$, respectively. As a result of concurrent determinations with both kits, it was found that the rate of positive cases positively correlated with increased tumor stage.

The rates for five tumor markers are summarized in Table 5. When any of four parameters were used, the rates of two positive markers to four markers were 64,70 and $93 \%$ in stages $\mathrm{G}_{1}, \mathrm{G}_{2}$ and $\mathrm{G}_{3}$ respectively, suggesting a linear correlation between tumor marker level and tumor size. Among any three of five positive tumor markers, any one of 4 were 53,65 and $94 \%$ in $G_{1}, G_{2}$ and $G_{3}$, respectively, suggesting the same tendency. In this regard, none of the healthy controls or the nontumor bearing patients (except for those with elevated ferritin levels caused by liver dysfunction), showed false-positive findings for tumor markers. A cut-off value was assigned in each stage for each tumor marker (Table 3). For comparison, the rates determined using the cutoff values conventionally used before induction (at $0 \mathrm{hr}$ ) are shown in Table 6. The positive rates per cases for any two of four markers was low, $11,14 \%$ and $55 \%$ at level of $\mathrm{G}_{1}, \mathrm{G}_{2}$, and $\mathrm{G}_{3}$ respectively, suggesting no correlation between the markers and tumor size. As shown in Table 6, when TMR was not induced, the correlations of the tumor marker parameters with a cancer stage from $G_{1}$ to $G_{3}$ were not confirmed.

\section{Practical application of a method to induce TMR in patients with poorly defined cancer}

A method for inducing TMR can facilitate the diagnosis of cancers that are difficult to diagnose morphologically or poorly differentiated cancers, as well as the diagnosis of cancers for which specific markers are unavailable. In fact, diagnosis can be made by the combined use of tumor marker combination assay (TMCA) that we developed. ${ }^{5}$ In clinical practice, a 30-year-old woman was given a diagnosis of poorly differentiated ovarian cancer in K. Medical University, and underwent 2 surgical operations and 4 chemotherapy sessions. She was diagnosed as having "no recurrence" by Professor N. President of the Japan Society of Obstetrics and Gynecology. However, this patient consulted with another professor because of her poor condition and was referred and admitted to our hospital. The results of TMR are shown in Table 7. 
Table 4 Determination of serum CEA, ferritin, $\alpha$-fetoprotein, sialic acid, and FT/Fe in cancer patients

\begin{tabular}{|c|c|c|c|c|c|}
\hline \multirow{2}{*}{ Tumor marker } & \multicolumn{3}{|l|}{ Cancer stage } & \multirow{2}{*}{ Normal subjects } & \multirow{2}{*}{ Cut-off used } \\
\hline & $\mathbf{G}_{1}$ & $\mathbf{G}_{2}$ & $\mathbf{G}_{3}$ & & \\
\hline \multicolumn{6}{|l|}{ CEA } \\
\hline$\Delta$ or $V \max$ & $36 / 61 \dagger,(64) \ddagger$ & $23 / 37(62)$ & $28 / 40(70)$ & $1 / 15(7)$ & 0.9 or 4.4 \\
\hline$\Delta / \mathrm{h}$ or $\Delta / \mathrm{h} \times V_{\max }$ & $37 / 6 I(6 I)$ & 27/37 (73) & $28 / 40(70)$ & $1 / 15(7)$ & 0.1 or 0.25 \\
\hline Either one of four & $42 / 61(69)$ & $30 / 37(81)$ & $31 / 40(78)$ & I/I5 (7) & \\
\hline \multicolumn{6}{|l|}{ FT SPAC-ferritin kit } \\
\hline$\Delta$ or $V \max$ & $12 / 28(43)$ & $\mathrm{I} \mathrm{I} / 20(55)$ & $|5 / 2|(7 \mid)$ & $3 / 10(30)$ & 20 or M:I50, F:65 \\
\hline$\Delta / \mathrm{h}$ or $\Delta / \mathrm{h} \times V \max$ & $13 / 28(46)$ & $13 / 20(65)$ & $|7 / 2|(8 \mid)$ & $4 / 10(40)$ & 0.8 or 50 \\
\hline Either one of four & I5/28 (54) & $13 / 20(65)$ & $|8 / 2|(86)$ & $4 / 10(40)$ & \\
\hline \multicolumn{6}{|l|}{ RIA-gnost FT kit } \\
\hline$\Delta$ or $V \max$ & 19/33 (58) & $1 \mathrm{I} / \mathrm{I} 7(65)$ & $16 / 19(84)$ & $0 / 5(0)$ & M:40, F:30 or M:200, F: 100 \\
\hline$\Delta / \mathrm{h}$ or $\Delta / \mathrm{h} \times V \max$ & 17/33 (52) & $10 / 17(59)$ & $13 / 19(68)$ & $0 / 5(0)$ & 4 or 800 \\
\hline Either one of four & $20 / 33(61)$ & I I/I7 (65) & $16 / 19(84)$ & $0 / 5(0)$ & \\
\hline \multicolumn{6}{|l|}{ SPAC and RIA } \\
\hline$\Delta$ or $V \max$ & $3 I / 6 I(5 I)$ & $22 / 37(59)$ & $31 / 40(78)$ & $3 / 15(20)$ & \\
\hline$\Delta / \mathrm{h}$ or $\Delta / \mathrm{h} \times V \max$ & $30 / 61$ (49) & $23 / 37(62)$ & $30 / 40(75)$ & $4 / 15(27)$ & \\
\hline Either one of four & $35 / 61(57)$ & $24 / 37(65)$ & $34 / 40(85)$ & $4 / 15(27)$ & \\
\hline \multicolumn{6}{|l|}{ AFP } \\
\hline$\Delta$ or $V \max$ & $\mathrm{II} / 6 \mathrm{I}(\mathrm{I})$ & $3 / 37(8)$ & $14 / 40(35)$ & I/I5 (7) & 5 or 10 \\
\hline$\Delta / \mathrm{h}$ or $\Delta / \mathrm{h} \times V_{\max }$ & $|2 / 6|(20)$ & $7 / 37$ (19) & I I/40 (28) & $0 / 15(0)$ & 0.6 or 3 \\
\hline Either one of four & $|5 / 6|(26)$ & $8 / 37(22)$ & $17 / 40(43)$ & I/I5 (7) & \\
\hline \multicolumn{6}{|l|}{ Sialic acid } \\
\hline$\Delta$ or $V \max$ & $22 / 30(73)$ & $14 / 17$ (82) & I5/18 (83) & $0 / 4(0)$ & 5 or 66 \\
\hline$\Delta / \mathrm{h}$ or $\Delta / \mathrm{h} \times V_{\max }$ & I7/30 (57) & 10/17 (59) & I5/I8 (83) & $0 / 4(0)$ & 0.5 or 30 \\
\hline Either one of four & $23 / 30(77)$ & 14/17 (82) & 16/18 (89) & $0 / 4(0)$ & \\
\hline \multicolumn{6}{|l|}{$\mathrm{FT} / \mathrm{Fe}$} \\
\hline SPAC & 8/28 (29) & $12 / 20(60)$ & $|6 / 2|(76)$ & $2 / 10(20)$ & 1 \\
\hline RIA & I7/33 (52) & I0/17 (59) & 16/19 (84) & $0 / 5(0)$ & 1.5 \\
\hline SPAC and RIA & $25 / 6 I$ (4I) & 22/37 (59) & $32 / 40$ (80) & $2 / 15(13)$ & \\
\hline
\end{tabular}

†No. of cases

$\ddagger$ Percent positive

Table 5 Comblination assay of serum CEA, FT, AFP, FT/Fe and or sialic acid in cancer patients who received TMR for tumors of various sizes

\begin{tabular}{|c|c|c|c|c|c|}
\hline & \multicolumn{3}{|c|}{ Cancer Stage } & \multirow{2}{*}{ Nonmalignment diseases } & \multirow{2}{*}{ Healthy individuals } \\
\hline & $\mathbf{G}_{1}$ & $\mathbf{G}_{2}$ & $\mathbf{G}_{3}$ & & \\
\hline \multicolumn{6}{|c|}{ Any two of four markers ${ }^{\dagger}$} \\
\hline$\Delta$ or Vmax & $54(33 / 6 I)^{\ddagger}$ & $62(23 / 37)$ & $88(35 / 40)$ & $18(2 / I I)$ & $0(0 / 4)$ \\
\hline$\Delta / \mathrm{h}$ or $\Delta / \mathrm{h} \times V_{\max }$ & $56(34 / 61)$ & $70(26 / 37)$ & $83(33 / 40)$ & $18(2 / 1 \mid)$ & $0(0 / 4)$ \\
\hline Either one of 4 & $64(39 / 61)$ & $70(26 / 37)$ & $93(37 / 40)$ & $18(2 /||)$ & $0(0 / 4)$ \\
\hline \multicolumn{6}{|c|}{ Any two of five markers $\S^{\S}$} \\
\hline$\Delta$ or Vmax & $73(22 / 30)$ & $76(13 / 17)$ & $94(17 / 18)$ & $n d^{\pi}$ & $0(0 / 4)$ \\
\hline
\end{tabular}


Table continued...

\begin{tabular}{|c|c|c|c|c|c|}
\hline \multirow[b]{2}{*}{$\Delta / \mathrm{h}$ or $\Delta / \mathrm{h} \times V \max$} & \multicolumn{3}{|c|}{ Cancer Stage } & \multirow{2}{*}{$\begin{array}{l}\text { Nonmalignment diseases } \\
\text { nd }\end{array}$} & \multirow{2}{*}{$\begin{array}{l}\text { Healthy individuals } \\
0(0 / 4)\end{array}$} \\
\hline & $67(20 / 30)$ & $76(13 / 17)$ & $94(17 / 18)$ & & \\
\hline Either one of 4 & $77(22 / 30)$ & $82(14 / 17)$ & $94(17 / 18)$ & nd & $0(0 / 4)$ \\
\hline \multicolumn{6}{|c|}{ Any three of five markers ${ }^{\S}$} \\
\hline$\Delta$ or $V \max$ & $50(15 / 30)$ & $59(10 / 18)$ & $94(17 / 18)$ & nd & $0(0 / 4)$ \\
\hline$\Delta / \mathrm{h}$ or $\Delta / \mathrm{h} \times \mathrm{V} \max$ & $47(14 / 30)$ & $47(8 / 17)$ & $78(14 / 18)$ & nd & $0(0 / 4)$ \\
\hline Either one of 4 & $53(16 / 30)$ & $65(11 / 17)$ & $94(17 / 18)$ & nd & $0(0 / 4)$ \\
\hline
\end{tabular}

†CEP, ferritin, AFP and FT/Fe

$\ddagger$ No. of Casesgiven in parantheses

$\S C E A, F T, A F P, F T / F e$ and or sialic acid

\Not determined

Table 6 Combination assay of tumor marker without TMR induction

\begin{tabular}{|c|c|c|c|c|c|c|c|}
\hline \multirow{2}{*}{ Tumor markers } & \multicolumn{6}{|c|}{$\%$ Positive } & \multirow{2}{*}{ Cut-off used } \\
\hline & $\mathbf{G}_{1}$ & & $\mathbf{G}_{2}$ & & $\mathbf{G}_{3}$ & & \\
\hline CEA & 20 & $(12 / 61) \dagger$ & 27 & $(10 / 37)$ & 53 & $(21 / 40)$ & $4.4 \mathrm{ng} / \mathrm{ml}$ \\
\hline \multicolumn{8}{|l|}{ FT } \\
\hline SPAC & 29 & $(8 / 28)$ & 45 & $(9 / 20)$ & 62 & $(|3 / 2|)$ & $\mathrm{F}, 65 ; \mathrm{M}, \mathrm{I} 50$ \\
\hline RIA & 45 & $(15 / 33)$ & 53 & $(9 / 17)$ & 84 & $(16 / 19)$ & $\mathrm{F}, \mathrm{I00} ; \mathrm{M}, 200(\mathrm{ng} / \mathrm{ml})$ \\
\hline SPAC and RIA & 38 & $(23 / 61)$ & 49 & $(18 / 37)$ & 73 & $(29 / 40)$ & \\
\hline AFP & 8 & $(5 / 61)$ & 3 & $(1 / 37)$ & 20 & $(8 / 40)$ & I0ng/ml \\
\hline Sialic acid & 30 & $(9 / 30)$ & 29 & $(5 / 17)$ & 56 & $(10 / 18)$ & $66 \mathrm{ng} / \mathrm{ml}$ \\
\hline \multicolumn{8}{|l|}{$\mathrm{FT} / \mathrm{Fe}$} \\
\hline SPAC & 0 & $(0 / 28)$ & 0 & $(0 / 20)$ & 10 & $(2 / 21)$ & 10 \\
\hline RIA & 0 & $(0 / 33)$ & 0 & $(0 / 17)$ & 11 & $(2 / 19)$ & 20 \\
\hline SPAC and RIA & 0 & $(0 / 6 I)$ & 0 & $(0 / 37)$ & 10 & $(4 / 40)$ & \\
\hline Any two of four markers & 11 & $(7 / 61)$ & 14 & $(5 / 37)$ & 55 & $(22 / 40)$ & \\
\hline Any two of five markers & 30 & $(9 / 30)$ & 29 & $(5 / 17)$ & 94 & $(17 / 18)$ & \\
\hline Any three of five markers & 3 & $(1 / 30)$ & 12 & $(2 / 17)$ & 39 & (7//8) & \\
\hline
\end{tabular}

$\dagger$ No. of cases is given in parentheses.

Table 7 TMR induction in the postoperative undifferentiated ovarian cancer patient

\begin{tabular}{|c|c|c|c|c|c|}
\hline TMR & $\mathbf{O h}$ & $6 \mathrm{~h}$ & $24 \mathrm{~h}$ & $48 \mathrm{~h}$ & \\
\hline CEA & 2.1 & 2.2 & 3.1 & 2.2 & $\begin{array}{l}\Delta \text { CEA (I.0), CEAmax } \\
(3.1)\end{array}$ \\
\hline Ferritin & 160 & 170 & 150 & 130 & $\begin{array}{l}\Delta \mathrm{FT} \text { (40ng), FTmax } \\
(\mathrm{I} 70)\end{array}$ \\
\hline $\mathrm{FT} / \mathrm{Fe}$ & 2.3 & 2.6 & 2.6 & 2 & $\mathrm{FT} / \mathrm{Fe}, \max (2.6)$ \\
\hline ALP & 130 & 122 & 129 & 122 & $\begin{array}{l}\operatorname{ALPmax}(130), \triangle A L P \\
\text { (8) }\end{array}$ \\
\hline LDH & 319 & 335 & 294 & 296 & $\begin{array}{l}\mathrm{LDH} \max (305), \Delta \mathrm{LDH} \\
\text { (4I) }\end{array}$ \\
\hline CAI5-3 & 12 & 13 & 14 & II & $\begin{array}{l}\text { CAI5-3 (14), } \triangle \text { CAI5- } \\
3(3)\end{array}$ \\
\hline $\mathrm{Fe}$ & 70 & 65 & 56 & 62 & $\mathrm{Fe} \max (56), \Delta \mathrm{Fe}(14)$ \\
\hline
\end{tabular}

Ribonuclease, 202U, NK activity (I7\%),T cell number (I468)

Albumin: $64 \%, \alpha$ I-globulin: $3.5 \%$

\section{Application results}

The TMR method was applied to this postoperative undifferentiated ovarian cancer patient.

The following data were obtained after TMR induction:

CEAmax: 3.1ng ( $\triangle$ CEA,1.0ng, $\Delta$ indicates the maximum change in value within 48 hours after induction: normal range within under 0.9ng), ferritin (FTmax): 170ng(normal range under 65ng), $\Delta \mathrm{FT}$ (40ng, normal range within $20 \mathrm{ng}), \mathrm{FT} / \mathrm{Fe}(\max ): 2.6,\left(\mathrm{G}_{2}\right.$ : normal range under 2.0. $\Delta \mathrm{FT} / \mathrm{Fe}: 0.6, \mathrm{LDH}: 294(\Delta 41 \mathrm{U}$, normal range within 30U), RNase (202U: normal range within 60-90U), alpha $(\alpha) 1$ globulin fraction: $3.5 \%$ (normal range within $2.2 \sim 2.6 \%$ ): and albumin: $64 \%$ (normal range $64 \sim 72 \%$ ) Table 7 . Tumor markers were evaluated by the TMCA technique, reported in the Cancer in $1994,{ }^{5}$ combined with the TMR induction technique. The more polished TMCA was reported in Cancer medicine. ${ }^{6}$ Based on the results obtained with these methods, the presence of cancer in the $\mathrm{G}_{2}$ clinical stage was estimated. Therefore, positron emission tomography (PET) and computed tomography $(\mathrm{CT})$ were performed and revealed metastasis in the right axillary lymph nodes $\square$ Virchow-lymph $\square$ node metastasis (+). The 
patient was given the herbal medicine: Sun Advance ${ }^{\circledR}$ which inhibits aerobic respiration by cancer cells, ${ }^{7,8}$ and detoxification therapy twice a week. As shown in Table 8, the patient was completely cured. As of 18 years after treatment, the patient has had no recurrence.

Table 8 The time course of the ovarian cancer patient

\begin{tabular}{lllllll}
\hline Date & Oct. I999 & Jul-00 & Jan. 200I & Feb. 2002 & Jan. 2005 & Jul- I 5 \\
\hline RNase & $202 \mathrm{U}$ & 147 & $\mathrm{III}$ & 99 & 99 & \\
$\begin{array}{l}\text { Thymidine kinase } \\
\text { Albumin (\%) }\end{array}$ & 64 & 67.4 & 65.1 & 65.2 & 62.9 & 6.7 \\
$\alpha-$ I globulin (\%) & 3.5 & 2.9 & 3 & 2.9 & 2.9 & 2.6 \\
NK activity (\%) & 17.8 & 24 & & 66 & & \\
TS risk assessment & $\mathrm{TS}\left(\mathrm{V}, \mathrm{G}_{2}\right)$ & $\mathrm{TS}\left(\mathrm{V}, \mathrm{G}_{1}\right)$ & $\mathrm{TS}\left(\mathrm{V}, \mathrm{G}_{1}\right)$ & $\mathrm{TS}\left(\mathrm{IV}, \mathrm{G}_{0}\right)$ & $\mathrm{TS}\left(\mathrm{IV}, \mathrm{G}_{0}\right)$ & $\mathrm{TS}(\mathrm{III})$ \\
PET scan & $(+)$ & & & & & \\
\hline
\end{tabular}

\section{Conclusions}

The presence and the size of hidden cancerous tumors can be estimated with tumor marker-release-related specific parameters with a combination treatment of vitamin A and hyperthermia.

\section{Acknowledgements}

I will express sincere gratitude to Kijima Chizuko, Dogome Miyoko, and Sugimoto Kimito.

\section{Conflict of interest}

The author declares that there is no conflict of interest.

\section{References}

1. Kitamura M, Ito S, Iimori I, et al. Normal value of the serum CEA by enzyme immunoassay. Igaku no Ayumi. 1980;112:519-521.

2. Kobayashi T, Kawakubo T, Jo T, et al. Elucidation of Tumor marker inducing mechanism. Newest Medicine. 1985;40:130-1303.
3. Kobayashi T, Dogome M, Kawakubo T. Increase in carcinoembryonic antigen release from cancer cells by combined treatment with retinoic acid and low-temperature hyperthermia. Int J Hyperthermia. 1990;6(4):785-92.

4. Kobayashi T. Correlation between Tumor Markers and Tumor Size. Cancer Detect Prev. 1987;10(1-2):81-87.

5. Kobayashi T, Kawakubo T. Prospective investigation of tumor markers and risk assessment in early cancer screening. Cancer. 1994;73(7):1946-1953.

6. Kobayashi T. A blood tumor marker combination assay produces high seensitivity and specificity for cancer according to the natural history of cancer. Cancer Med. 2018;7(3):549-556. $\square$

7. Sugimoto K. et al. The effect of the anti-tumor herb medicine Sun Advance in mice. Proc Symp WAKAN YAKU. 1982;15:224-227.

8. Tanimizu T, et al. New approach to Chinese herb medicine, inhibition by Chinese herb medicine" Sun Advance" of SV40 transformation in mouse cells. Proc Symp WAKAN YAKU. 1982;15:228-233. 